\title{
FACTORES BÁSICOS EN MATERIA DE RESTITUCIÓN DE TIERRAS FRENTE AL DESPLAZAMIENTO FORZADO *
}

\section{Basic factors regarding land restitution in the face of forced displacement}

Jaime Alberto Sandoval Mesa**, Edwin Jesith Bernal Ramírez ${ }^{* * *}$

Omar Antonio Herrán Pinzón****, Norhy Esther Torregrosa Jiménez ${ }^{* * * *}$

Rodolfo Alfonso Torregrosa Jiménez ${ }^{* * * * *}$

Recepción: 23 de marzo de 2021. Aceptación: 29 de septiembre de 2021.

DOI: http://dx.doi.org/10.21017/Rev.Repub.2021.v31.a109

* Artículo de colaboración y cohesión del Grupo de Investigación Derecho Público de la Universidad Militar Nueva Granada y del grupo de investigación Derecho, Sociedad y Estudios Internacionales de la Universidad Libre, Seccional Bogotá.

* Doctor en Derecho, PhD. USTA (2017). Magíster en Derecho Penal USTA-U. Salamanca (2010). Especialista en Derecho Público UNAL (2002), D. Penal (1998) y D. Constitucional (2002). Abogado USTA (1997). Líder del Grupo de Derecho Público UMNG. Investigador asociado de Colciencias (I). Líder de la Línea Derecho Penal y Justicia Militar, docente del área penal, Facultad de Derecho UMNG. Artículo de investigación proyecto 3162 Vice Inv. Der. UMNG. Vigencia 2020-2021. Correo electrónico: jaime.sandoval@unimilitar.edu.co

*** Abogado de la Universidad Externado de Colombia, doctorante en Estudios Sociales de la Universidad Distrital Francisco José de Caldas, magíster en Derechos Humanos de la Universidad Pedagógica y Tecnológica de Colombia, especialista en Mercados y Políticas de Suelo en América Latina de la Universidad Nacional de Colombia, maestrando en Propiedad Intelectual de la Facultad Latinoamericana de Ciencias Sociales (FLACSO), Argentina. Actualmente se desempeña como docente de tiempo completo en la Universidad Militar Nueva Granada. Artículo de investigación proyecto 3162 Vice Inv. Der. UMNG. Vigencia 2020-2021. Correo electrónico: edwin.bernal@unimilitar.edu.co.

**** Docente de la Facultad de Derecho de la Universidad Militar Nueva Granada, sede Bogotá. Investigador del grupo de Derecho Público, línea de Derecho Penal, del Centro de Investigaciones Jurídicas, Políticas y Sociales de la Facultad de Derecho. Abogado de la Universidad Militar Nueva Granada y magíster en Derecho Procesal Penal de la misma institución. Correo electrónico: omar.herran@unimilitar.edu.co. Artículo de investigación proyecto 3162 Vice Inv. Der. UMNG. Vigencia 2020-2021.

***** Doctora en Derecho, Universidad Externado de Colombia. Docente investigadora de la Universidad Libre, seccional Bogotá, pertenece al grupo de investigación «Derecho, sociedad y estudios internacionales». CVLAC: https://bit.ly/31znkbz,ORCID: 0000-0003-1445-2166. Correo electrónico: norhys.torregrozaj@unilibre.edu.co.

****** Doctor en Sociología Jurídica de la Universidad Externado. Docente investigador de la Universidad Libre, seccional Bogotá, pertenece al grupo de investigación «Derecho, sociedad y estudios internacionales». CVLAC: https://bit.ly/2N6Dm7E,ORCID:00000001-6369-8547.Correoelectrónico: rodolfoa.torregrosaj@unilibre.edu.co. 


\title{
RESUMEN
}

En el presente artículo se analiza el proceso de restitución de tierras, que tiene como característica un fenómeno sistemático de pérdida patrimonial sufrido por las víctimas en sus bienes sujetos a registro. Todo ello debido a modalidades empleadas tanto por actores de personas naturales como de personas jurídicas, vinculados a las afectaciones de despojo, junto con las diversas consecuencias que se generan en tal virtud como por ejemplo en los casos de desplazamiento forzado hacia las ciudades en Colombia. En este sentido, es posible advertir que inicialmente este aspecto se refleja en los campesinos víctimas de la violencia, y que a través de un fenómeno de diáspora se extiende a todo tipo de fenómeno social. Así mismo se pretende identificar si a partir del fenómeno mencionado, los instrumentos legales son suficientes para evidenciar la responsabilidad tanto de personas naturales como jurídicas que se ven asociadas al fenómeno del despojo.

Palabras clave: restitución, tierras, desplazamiento forzado, cuestión agraria, despojo.

\begin{abstract}
This article analyzes the land restitution process, which is characterized by a systematic phenomenon of patrimonial loss suffered by victims in their property subject to registration. All of this, due to the modalities used by both natural persons and legal entities, linked to the effects of dispossession, together with the various consequences that are generated by such virtue, such as in cases of forced displacement to cities in Colombia. In this sense, it is possible to notice that initially this aspect is reflected in the peasant victims of violence, which through a diaspora phenomenon extends to all types of social phenomenon.

Likewise, it is intended to identify, if from the phenomenon, the legal instruments are sufficient to demonstrate the responsibility of both natural and legal persons that are associated with the phenomenon of dispossession.
\end{abstract}

Key words: restitution, land, forced displacement, agrarian issue, dispossession.

\section{INTRODUCCIÓN}

Después de 60 años de conflicto armado en Colombia, se iniciaron dos procesos transicionales que tienen su origen desde el año 2005. Esta primera justicia transicional en Colombia fue creada mediante la Ley 975 de 2005. A partir de allí, en el año 2007, la preocupación por las decisiones de estos mecanismos se 
inició con al apoyo de entidades internacionales. Las mismas tendían a prestar asesoría para obtener resultados eficientes en la jurisdicción mencionada. Posteriormente, después del acuerdo de paz de 2016, se estableció otro mecanismo de justicia transicional en Colombia con el mismo propósito de justicia, verdad, reparación y garantías de no repetición.

Bajo la anterior estructura transicional, la decisión judicial todavía es insuficiente para determinar los elementos de justicia que se asocian a los derechos de las víctimas, en particular los derivados del desplazamiento forzado y el despojo de tierras. En el momento se avanza hacia el conocimiento social de estas decisiones, mediante los trabajos de la Unidad de Restitución creada en el año 2011 (Ley 1448), con sus sentencias que son objeto de estudio en la actualidad.

Pero además si bien se estudia el problema fáctico del hecho, sobre este aspecto aparece separado el concepto respecto de autores y partícipes de los hechos del despojo que todavía tienen un alcance punitivo. En tal virtud este aspecto último de justicia sigue alejado de las conductas y de las medidas de reparación que constituyen el centro específico de atención de la justicia transicional, aspecto que se desarrolla en los siguientes fundamentos.

\section{LOS ELEMENTOS BÁSICOS DEL CONCEPTO DE RESTITU- CIÓN A PARTIR DEL CONTEXTO}

En concreto, hablar de tierras, despojo y campesinado en Colombia es hacer un recorrido por la inagotable fuente de causas objetivas del conflicto mismo, además de las muchas tareas pendientes de la conformación del Estado moderno colombiano, porque la guerra en Colombia en su gran mayoría se ha desarrollado o ha tenido como teatro de operaciones las zonas rurales del país, llevando a que el despojo de tierras sea una constante por diversas fracturas internas sociales. Las mismas se vienen presentando desde la primera violencia en Colombia que se puede establecer a partir de 1948; sin embargo, las causas políticas y sociales pueden ubicarse entre 1910 y 1930, en un profundo control de la propiedad por parte de los latifundios y un desamparo de los campesinos en todas sus garantías, en una situación de inequidad, estado que permanece hasta la actualidad (Prieto Sanjuan y Sandoval Mesa, , 2020).

\subsection{El conflicto armado y la Cuestión Agraria}

En el análisis teórico formativo de categorías de análisis de las formas agrarias en las que se pretende discutir las profundas dinámicas del problema del 
campesinado y la tenencia como fundamento del conflicto violento, se puede observar en el trabajo de Orlando Fals Borda, que identificó una falencia estructural en el sentido de la tenencia de la tierra, en la construcción de lo agrario y de los sujetos-campesinos, en el territorio colombiano. En este estudio sobre la violencia en Colombia se concluye que el movimiento migratorio y el despojo se producen por el factor violencia que obliga al campesinado al abandono de sus posesiones y sus lugares de origen (Fals Borda, et al. 1978, págs. 93 a 123).

Esto produjo el primer factor de despojo y a su vez una conducta sistemática que no ha cesado en la actualidad que se constituye en la migración forzada como el primer elemento estructural. A esto se le denomina desplazamiento por temor, porque la comunidad queda debilitada y dividida y por lo tanto, se disminuye el porcentaje de denuncia contra las acciones y/o agresiones que van desde intimidaciones y múltiples actos de violencia (Sandoval Mesa y Ubajoa Fierro, 2020).

Bajo este panorama, es indudable que el punto de partida desde el terreno de los grupos subversivos se trazó a partir de las medidas políticas bajo una visión de cambio social y mayor distribución en el campo de la tierra, para comprender el territorio como escenario de representación, resignificación, y lucha política, jurídica y cultural (GMH,2013, págs. 76 y 77).

Esta causa social fue la que aglutinó el surgimiento inicial de la subversión hacia la década de los años sesenta en Colombia y lo que posteriormente se presentó en los años ochenta con el surgimiento de los grupos de autodefensa. En tal virtud, es posible afirmar que en primera instancia «el conflicto, la violencia y la estructura social colombiana identifica a los grandes latifundios con la cuestión agraria en el desarrollo del conflicto colombiano vinculando a estos dos actores mencionados» (GMH, 2013, pág. 118).

En esta visión del conflicto, se puede observar que desde sus inicios no basta con la restitución que al final aporta una labor de reparación; se hace necesario identificar a los autores y participes de las principales conductas asociadas al despojo y al desplazamiento forzado, al igual que otras conductas relacionadas como el fraude procesal, falsedades, etc., elementos que son necesarios para la ejecución de esta forma de migración forzada vinculada al Conflicto (Sandoval Mesa y Ubajoa Fierro, 2020, págs. 14 a 16).

\subsection{Factores de criminalidad asociados al despojo y al desplazamiento forzado}

Este punto es necesario, pues en el conflicto armado colombiano confluyen tanto los factores de macro criminalidad como las personas jurídicas y las or- 
ganizaciones de tipo criminal. En muchos casos se advierte que todo este proceso no sería pregonable en estricto sentido en uno u otro campo, vale decir las personas jurídicas, su responsabilidad y los procesos de macro criminalidad y aparatos organizados de poder. No obstante, la naturaleza especial del contexto nacional revela que existían nexos en este sentido, por ejemplo, en los casos de parapolítica. Frente a este punto vale la pena citar la masacre de Macayepó, que tuvo como determinador al congresista Álvaro García (Corte Suprema de Justicia, Sala de casación penal. 23.02.2010. M. P. Leónidas Bustos Ramírez).

En esta decisión se observa la connivencia entre grupos armados y particulares debido a los actos de violencia que produjeron múltiples homicidios y desplazamiento de personas, junto con la relación entre el procesado y el grupo armado irregular que realizó la incursión, entre el 9 y el 16 de octubre de 2000 en diversos corregimientos de Carmen de Bolívar (Bolívar), entre ellos la región de los Montes de María (Corte Suprema de Justicia, Sala de casación penal. 23.02.2010. M. P. Leónidas Bustos Ramírez).

Lo anterior revela por ejemplo que en aplicación de las cláusulas del Acuerdo de Paz de 2016 se requiere en forma imperante una reforma agraria no solo para dar cumplimiento a tales cláusulas sino también para evitar las conductas masivas de actores armados que, vestidos de poder para incidir a nivel regional y local, permiten no solo el despojo sino la violencia por temor -como lo mencionaba Fals Borda - , más de cincuenta años atrás a causa de tales prácticas que permanecen hasta la actualidad.

Así mismo, también expertos como Gutiérrez F. (2014) empiezan a dar aún más orientaciones de como la tierra y el despojo se da también desde luchas de tipo jurídico que deben ser sometidas a historias sociales y miradas constitutivas de las formas de estado y las respuestas del aparato jurídico con sus materiales para escindir o no las disputas por el territorio (Gutiérrez F. 2014). En este campo, es posible establecer que se presentó un patrón de macro criminalidad, que coincide con la identificación en el curso de investigaciones realizadas, con la existencia de aparatos y grupos criminales que actúan en contextos de graves y masivas violaciones de DD HH (Sandoval Mesa, 2017, pág. 14).

A nivel comparado este tipo de grupos es plenamente identificable en conflictos sociales en otras naciones en casos de masivas violaciones de Derechos Humanos y crímenes internacionales de tal naturaleza. Sobre este aspecto es viable citar el caso de la República Democrática del Congo, en el cual, la Corte Penal Internacional reconoce que los crímenes cometidos a nivel internacional son manifestaciones de criminalidad colectiva. Estas conductas 
llevadas a cabo por un grupo de individuos que actúan bajo un diseño criminal común, en casos como por ejemplo Thomas Lubanga y Germain Katanga, establece la existencia de este grupo que además de reclutamiento forzado, tenía por objeto la comisión de delitos de lesa humanidad (Situation in the democratic Republic of the Congo in the case of the Prosecutor v. Thomas Lubanga Dyilo, sentencia de 10 de julio de 2012; Sandoval Mesa, 2018, págs. 218 a 220). Así mismo, en el caso de Germain Katanga, el 7 de marzo de 2014, la mayoría de la Sala de Primera Instancia II encontró culpable como accesorio, con un cargo de crímenes de lesa humanidad (asesinato) y 4 cargos de crímenes de guerra - ataques en contra de una población civil, asesinato, destrucción de propiedad del enemigo y saqueo-. (Sandoval Mesa, 2018, págs. 218 a 220).

En este caso se encontró que la potencialidad de actos contra la población civil revela el nivel de afectación de violencia en casos similares a nivel internacional (Situation in the democratic Republic of the Congo in the case of the Prosecutor v. Germain Katanga, Sentencia de 4 de abril de 2014).

$\mathrm{Al}$ igual que en el caso colombiano se pueden identificar dirigentes y superiores de grupos armados con posiciones privilegiadas frente a la ejecución y puesta en marcha de políticas militares o de grupos armados ilegales. Es decir, el nivel de organización independiente del caso comparado tiene una formalidad similar en cuanto a la estructura de las organizaciones criminales que les permite realizar sus acciones delictivas. Es decir, se trata de una base estructural de líderes con poderes de controlar territorios y un número de subalternos que pueden ser sustituibles y difíciles de identificar en cada ejecución del plan, que en muchos casos es sistemático (Sandoval, 2017, pág. 14). No obstante, esta base es necesaria para determinar las acciones posteriores a la penalización de las conductas criminales, que en todo caso es insuficiente, en la medida en que la capacidad de persecución contra estas organizaciones es necesaria para determinar los actos posteriores de restitución.

Finalmente, también aparece un enfoque que busca un concepto transformador y participativo desde las reparaciones en materia de justicia transicional, que apunta a descifrar cómo en el contexto actual colombiano se necesita del orden jurídico (Uprimny-Yepes y Sánchez, 2010, pág. 305), para construir tanto la paz como la posibilidad de dirimir unas nuevas dinámicas sobre los crímenes de desplazamiento y los asociados al despojo, la tenencia de la tierra y las luchas por el poder, en un intento por trazar el mapa de la restitución en términos tanto de contexto social como jurídico (Uprimny-Yepes, R. y Sánchez, 2010, pág. 305). 


\section{FUNDAMENTOS INICIALES DE LA RESTITUCIÓN DE TIE- RRAS Y PERSECUCIÓN DE SUS AUTORES}

En el proceso de restitución de tierras, se refleja a su vez el desplazamiento forzado hacia las ciudades en Colombia. Este fenómeno de violencia se caracteriza por que confluyen dos tipos de graves violaciones que residen en el despojo de tierras como son el desplazamiento forzado y todos los atentados contra la vida asociados a este fenómeno. Las conductas que se reflejan en acciones criminales afectan bienes jurídicos como la vida, la integridad personal, los derechos patrimoniales, las libertades personales y sexuales, entre otros derechos afectados.

En muchas de las denuncias que han sido presentadas ante la Fiscalía General de la Nación y todos los centros de observación de derechos de víctimas se analizan pérdidas de cultivos, ganaderías, actividades económicas conexas con el agro y, por supuesto, cómo ha sido el comportamiento sobre el despojo de tierras. Así mismo, las consecuencias del abandono o transferencia de tierras a título traslaticio de dominio. En los casos sometidos a examen se identifica la transferencia de tierras que son obtenidas fraudulentamente, producto de actos antecedidos por la violencia, bien por la amenaza o por la coerción que ocasionan todos los grupos creadores de violencia en Colombia como por ejemplo los grupos de autodefensas, organizaciones criminales, GAO, carteles de narcotráfico, entre otros, como se observa en decisiones judiciales que revelan este patrón sistemático de violaciones (Corte Suprema de Justicia, Sala de casación penal. 23.02.2010. M. P. Leónidas Bustos Ramírez; Tribunal Superior del Distrito Judicial de Bogotá, Sala de Justicia y Paz, M. P. Uldi Teresa Jiménez López, Sentencia de 29 de junio de 2010).

Para tal efecto, como en casi todos los fenómenos promotores de violencia en Colombia, las medidas legales crearon un sistema complejo de tipo jurídico para adelantar el proceso de restitución. Se ha pensado que un sistema seguro jurídico puede generar mejores resultados que los recursos existentes, sobre todo por la naturaleza especial del despojo de tierras que mezcla tanto factores de índole constitucional, punitivo, como de derecho administrativo y de Derecho Privado. En este sentido el alcance de las medidas destinadas al proceso de restitución de tierras fue consagrado por vez primera en Colombia mediante la Ley 1448 de 2011 y en los decretos 4633, 4634 y 4635 de 2011; el Decreto 1725 de 2012; el Decreto 3011 de 2013; el Decreto 698 de 2013; el Decreto Único Reglamentario 1084 de 2015; el Decreto 1071 de 2015, y el Decreto 440 de 2016. En todas ellas se crea un sistema que permite el retorno y combatir la titulación ilegal en el escenario del conflicto armado. 
Así mismo en el acuerdo de paz entre el Gobierno de Colombia y las FARCEP, los puntos primero (Reforma Rural Integral) y quinto (Víctimas. Sistema Integral de Verdad, Justicia, Reparación y No Repetición) contienen disposiciones referentes a garantizar los derechos de las víctimas del conflicto armado interno que padecieron el despojo y el abandono de tierras Acuerdo final para la terminación del conflicto y la construcción de una paz estable y duradera. (2016). Este aspecto todavía merece desarrollos posteriores que son necesarios para armonizar toda esta legislación con los efectos de las decisiones sobre reconocimiento de responsabilidad que en este sentido se generen en la jurisdicción especial para la paz.

En general el abandono y el despojo de tierras ha sido sintetizado en prácticas generalmente realizadas por los actores armados del conflicto, papel en el cual se cuestiona si en dichas conductas han participado empresas y personas jurídicas. Para tal efecto es preciso definir que los actores del conflicto pueden ser clasificados tanto dentro de los miembros de los grupos armados ilegales como de los agentes estatales. Pero además como la naturaleza del conflicto nacional es compleja, también es necesario adicionar a los particulares que de alguna manera participaron en el conflicto a través de las prácticas ilegales que son objeto de estudio (Centro Nacional de Memoria Histórica 2015, pág. 122).

Sobre el particular, se analiza si han sido instigadores para lograr que legítimos propietarios poseedores de buena fe $\mathrm{u}$ ocupantes de predios enajenen, entreguen, se desplacen o sencillamente abandonen la tierra dándoles apariencia de legalidad a través de negocios jurídicos que son producto de concurso de delitos inherentes a objetos y causas ilícitas (Centro Nacional de Memoria Histórica 2015, pág. 122).

En este sentido, en los casos sometidos a examen se identifica la transferencia de tierras que son obtenidas fraudulentamente, producto de actos antecedidos por la violencia, bien por la amenaza o por la coerción que ocasionan todos los grupos creadores de violencia en Colombia (autodefensas, organizaciones criminales, GAO, carteles de narcotráfico, entre otros). Por ejemplo, se puede citar el caso ocurrido en el corregimiento de Mampuján, el 10 de marzo de 2000, donde un grupo armado de paramilitares desplazaron a varias familias del lugar. El hecho tuvo lugar en la vereda San Juan Nepomuceno sobre el predio Las Brisas, y el desplazamiento y el despojo de tierras se produjeron hacia Carmen de Bolívar y Cartagena. En este caso se ordenó el retorno y la restitución a las víctimas objeto del despojo (Juzgado Segundo Civil del Circuito Especializado en Restitución de tierras, Sentencia de restitución de 27 de junio de 2013, Demanda Unidad de Restitución). 


\section{PROTECCIÓN CONSTITUCIONAL DE VÍCTIMAS}

En lo referente a la restitución de tierras, como componente de la reparación a las víctimas (Corte Constitucional, T-679 de 2015), se ha implementado en Colombia desde el año 2011, aún sin que haya cesado el conflicto armado interno (Ministerio de Agricultura, 2014, noviembre 24).

En este sentido, desde el año 2011, con la expedición del Decreto 4801 del Departamento Administrativo de la Función Pública, se estableció la estructura y las funciones de la Unidad Administrativa Especial de Gestión de Restitución de Tierras Despojadas, UAEGRTD. Esta nueva entidad estatal fue creada en virtud del artículo 103 de la Ley 1448 de 2011 por un periodo de 10 años contados a partir de su promulgación, la cual recientemente ha sido renovada mediante la Ley 2078 de 2021 por otros 10 años. Para los fines de los acuerdos de paz de 2016 es necesario armonizar estas disposiciones para orientar los procesos de restitución que sean expuestos en este sentido, mediante sus mecanismos especiales, y de paso dar cumplimiento a las obligaciones pactadas en el acuerdo.

La Unidad de Restitución de Tierras (UAEGRTD) es una entidad estatal «adscrita al Ministerio de Agricultura y Desarrollo Rural» de Colombia (Ley 1448, 2011) con personería jurídica y autonomía administrativa. Respecto a sus funciones, estas se centran en la «conformación administración» y conservación del Registro de Tierras Despojadas y Abandonadas Forzosamente, RTDAF (Decreto 4801, 2011).

En dicho registro se podrán inscribir las personas que hubieren sufrido el despojo o abandono de tierras como hecho victimizante. Así mismo se registran los predios abandonados o despojados debido al conflicto armado interno desde el $1 .^{\circ}$ de enero de 1991. En este sentido la unidad especial administrativa se encarga de resolver los diferentes conflictos relacionados con el problema del despojo, pero a su vez carece de medidas coercitivas efectivas que permitan identificar a los actores principales. Tan solo se revelan los actos relacionados con los predios y si al caso el retorno del predio a su propietario; por ende, las decisiones judiciales punitivas en este sentido constituyen un refuerzo jurisdiccional para la efectividad de tales medidas.

La Unidad (UAEGRTD) adelanta el trámite administrativo de restitución de tierras, el cual termina con la inscripción o no en el Registro de Tierras Despojadas y Abandonadas Forzosamente. Este registro es requisito de procedibilidad para adelantar posteriormente la etapa judicial ante los jueces especializados en restitución de tierras. Posteriormente se inicia un proceso judicial que en realidad trata de identificar los aspectos que generaron el acto de despojo, 
pero los mecanismos sistemáticos del asunto requieren de un análisis de contexto que por ahora solo se realiza en informes del conflicto, pero su característica es la generalidad de sus conclusiones frente al problema.

La inscripción en el Registro de Tierras Despojadas y Abandonadas forzosamente fue analizada por la Corte Constitucional, la cual encontró que es una medida que no vulnera los derechos de las víctimas, es «adecuada, idónea, necesaria y proporcional en sentido estricto, para alcanzar los fines de restitución que se propone la norma» (Corte Constitucional, C-715 de 2012). En este sentido, el requisito de procedibilidad para instaurar la solicitud de restitución, ante los jueces competentes, no vulnera el derecho al acceso a la justicia ni el debido proceso de los reclamantes de tierras. Si bien constituye el primer paso en reconocer la titularidad de los bienes perdidos, apenas es el comienzo del proceso de reclamación y retorno a los predios despojados (Corte Constitucional, C-715 de 2012).

Adicionalmente, como se mencionó, la Unidad de Restitución de Tierras (UAEGRTD) tiene la competencia para instaurar la solicitud de restitución o formalización ante los jueces especializados en restitución de tierras, representando a las víctimas del conflicto armado interno que sufrieron de despojo o abandono forzado a partir de 1991. Cabe destacar que la decisión sobre la restitución de un determinado predio corresponde al juez, quien fallará en derecho de acuerdo con las pruebas aportadas por las partes y las solicitadas de oficio, en un proceso judicial donde se garantiza el derecho de contradicción a los opositores.

Resulta relevante señalar que la restitución de tierras no se adelanta actualmente en todo el territorio nacional sino en aquellas regiones donde existen condiciones de seguridad que permitan adelantar los procesos de documentación del caso y los retornos de la población. En este caso se presenta una contingencia que afecta el reclamo y la obtención de los derechos de propiedad en zonas donde sistemáticamente continúa tanto el despojo como el conflicto armado.

Si bien esto responde al contexto de este país, esta situación lleva a que muchas solicitudes de restitución aún no puedan ser estudiadas y por lo tanto «tampoco se podrían restituir» (Álvarez, et al., 2014, pág. 115). Cabe resaltar que en virtud de la Sentencia T-679 de 2015 se ordenó a la Unidad de Restitución de Tierras elaborar un plan de intervención en el que deberá incorporar los objetivos y las estrategias para restituir todos los predios despojados en el plazo de 10 años del que trata la Ley 1448 de 2011. No obstante, es preciso analizar que en este proceso no se menciona la posibilidad de articulación de dichos actos con autoridades judiciales como la Fiscalía General de la Nación, por 
ejemplo, para adelantar actuaciones conjuntas con miras a identificar el análisis de contexto del problema que revela múltiples relaciones en el caso preciso del despojo de tierras.

Lo anterior implica que el Gobierno debe coordinar las instancias que intervienen en el proceso de focalización, con el propósito de evitar cualquier tipo de desarticulación institucional (Corte Constitucional, T-679 de 2015). En el momento, el plan en este sentido sigue pendiente y debe ser objeto de desarrollo. Sin embargo, como ya se dijo, la magnitud del asunto puede rebasar la capacidad operativa de la Unidad de Restitución de Tierras.

Un factor importante son las cifras, ya que a 30 de julio de 2018, se ha logrado la restitución de 303.642 hectáreas a favor de las víctimas del conflicto armado interno; así mismo, los jueces y/o magistrados especializados en restitución de tierras han proferido 4200 sentencias (Información recabada por la UAEGRTD, 2018 , julio 30). Este punto es importante, pues no se trata de un número menor de restitución, sino que el problema es la magnitud del territorio despojado, que frente a estas cifras es todavía inmenso.

La Unidad de Restitución de Tierras despojadas en la actualidad se ha consolidado como una referente internacional para implementar este tipo de política pública a favor de las víctimas, como por ejemplo frente a casos de naciones también afectadas por esta problemática como Kenia, Argentina, Honduras, Filipinas, etc. Pese a todos estos resultados, lo conveniente es verificar no solamente que se ha producido el despojo sino las conductas que han permeado este fenómeno en Colombia. Esta labor se encuentra pendiente sobre todo porque corresponde a los mecanismos de justicia transicional que han sido implementados en Colombia.

\section{EXPERIENCIAS EN MATERIA DE RESTITUCIÓN DERIVA- DAS DE CONFLICTOS ARMADOS Y FACTORES DE DESPLAZAMIENTO}

Uno de los aportes principales de la Unidad de Tierras (UAEGRTD) consiste en apoyar los procesos de reparación integral de las víctimas, mediante las gestiones administrativa y judicial. Así mismo su participación en las actividades posfallo han sido relevante en las solicitudes de restitución de tierras. Estos actos permiten generar confianza en los campesinos que han regresado a sus tierras para cultivarlas y ayudar con el desarrollo sostenible del país. Esto es relevante toda vez que en las sentencias de restitución los jueces y/o magistrados han ordenado a esta entidad la implementación de proyectos productivos, el alivio de pasivos en impuesto predial y servicios públicos 
domiciliarios, la priorización de subsidios de vivienda, la asistencia técnica integral a favor de las víctimas de despojo o abandono forzado, etc. (UAEGRTD, 2017, pág. 49) ${ }^{1}$.

En el caso de experiencias en el terreno, se constataron predios restituidos en Sucre y Córdoba, así como también se tuvo un diálogo directo con las personas que han sido reparadas en el componente de restitución de tierras. Se destacaron los programas de seguridad alimentaria promovidos de manera posterior a la entrega de predios, gracias a los proyectos productivos que son otorgados en las sentencias de restitución (Bernal, 2016). Es decir, a pesar de las críticas sobre sus resultados, lo anterior revela que es importante que se realicen y lleven a cabo, hasta el nivel de restitución de la tierra, los casos adelantados, que en muchos casos son derivados de masacres cometidas en Colombia.

Sobre este punto, a la visita mencionada se puede adicionar que se hizo en asocio con la Comisión Nacional de Tierras de Kenia (2014), sobre restitución de tierras y políticas públicas. En este caso se destacaron los beneficios que se otorgan a las víctimas a partir de la normativa especial en Colombia, sobre todo si se conoce que la situación puede ser similar en otros conflictos como por ejemplo los de África.

En este escenario, cambia la situación que imperaba hace unos años, en la cual eran los grupos al margen de la ley y los dueños de latifundios los que dirimían los conflictos en el campo, muchas veces por la fuerza. Esta función se trasladó a los jueces y/o magistrados especializados de restitución que tienen la posibilidad de garantizar la seguridad jurídica de la propiedad de la tierra, formalizando a los poseedores y ocupantes de predios rurales. En este sentido, se pudo determinar por ejemplo en casos específicos cómo la actividad ganadera y el despojo de tierras estaban relacionados con el conflicto armado y la presencia de cultivos ilícitos en la región en un lapso entre el 2000 y 2009, situación que impidió el desarrollo económico en la región, conforme a las cifras estatales sobre el conflicto armado en el Departamento del Meta (Duarte Rojas y Cote Poveda, 2013, pág. 26).

Por otra parte, es importante mencionar que existen procedimientos diferentes para adelantar los procesos de restitución a favor de los sujetos colectivos de derechos mediante el derecho fundamental de Restitución de Tierras. Esto representa la consideración de derechos humanos efectivos para las víctimas

1 Así, a corte de 31 de diciembre de 2017, la Unidad de Restitución ha otorgado \$78.965.000 en 17 departamentos del país, beneficiando a 3.148 familias. 
en relación con grupos vulnerables en el escenario del Conflicto Armado como un factor necesario de resolución, toda vez que la causa proviene, en estos casos, de variables que partieron de la situación frente al desplazado. Esto en la medida en que no solo este es despojado de su tierra, o de sus pertenencias, de su parcela, ganado y demás bienes, sino también despojado al ser expulsado de su entorno, de su vida tal como la conocía anteriormente para comenzar una nueva vida (CNMH, 2015, pág. 20).

En tal virtud, el reconocimiento del derecho a la restitución de tierras de las víctimas «está vinculado a tres nociones básicas: al concepto de víctima del conflicto, al concepto de desplazado víctima del conflicto, y la reparación integral como derecho fundamental del que son titulares las víctimas del conflicto» (Quinche et al., 2015, pág. 28).

En efecto, desde la Sentencia T-025 de 2004 se protegió los derechos de la población en situación de desplazamiento forzado, se declaró el estado de cosas inconstitucional, debido a la vulneración masiva y generalizada de los derechos fundamentales de la población desplazada. Sobre este punto, es importante destacar que además de este proceso, al mismo tiempo, se trata de seguir los principios del migrante forzado y su derecho al restablecimiento. (Sandoval Mesa y Ubajoa Fierro, 2020).

Lo anterior resulta pertinente en la medida en que la construcción del derecho al establecimiento del desplazado, más allá de la tenencia de un lugar para vivir o una posesión de tierras, implica su protección y prevención; de allí las medidas que se requieren en el momento del desplazamiento y luego al final, cuando se produce el regreso, reasentamiento o reintegración (Sandoval Mesa y Ubajoa Fierro, 2020). Por tal razón, las medidas de restitución resultan pertinentes si tienen la potencialidad de lograr estos momentos de protección y restablecimiento.

Frente a estos puntos, se contrapone la falta de expedición de leyes, medidas administrativas, presupuestales, para garantizar la asistencia, la atención y la reparación a los desplazados (Corte Constitucional, T-025 de 2004); constituye uno de los puntos frágiles que surgen de esta problemática, pero en materia de restitución, permite adicionar este punto todavía pendiente para la protección y el establecimiento de la población desplazada (Sandoval Mesa y Ubajoa Fierro, 2020). Sin embargo, la situación en la relación de desplazamiento forzado y restitución tiene la controversia en torno a la necesidad de restituir al desplazado; pero también en muchos casos la víctima ha tenido arraigo en otro lugar. Esta variable todavía es difícil de consensuar en este diálogo (Sandoval Mesa y Ubajoa Fierro, 2020). 
Por esta razón, la sentencia anterior permite dar los lineamientos referentes a la asistencia, la atención y la reparación a las víctimas de desplazamiento. Se constató que el Estado no había diseñado un sistema para registrar los predios despojados o abandonados con ocasión del conflicto armado interno y tampoco existían programas que garantizaran el retorno a los desplazados. Todo ello por cuanto en esta materia, las acciones penales de persecución de este delito no se encuentran armonizadas con las medidas de reparación y restitución. Al parecer estos dos pilares transicionales se encuentran separados por jurisdicciones diferentes dada la naturaleza penal de un lado y la mixta civil y administrativa del otro (Sandoval Mesa y Ubajoa Fierro, 2020, pág. 76).

La Corte Constitucional en esta sentencia ordenó adelantar acciones para garantizar el goce efectivo de los derechos de la población desplazada, crear programas de estabilización socioeconómica, otorgar ayudas humanitarias, atención en salud, acceso al sistema educativo a favor de las víctimas de desplazamiento. Se trata de un argumento de justicia social para las víctimas que en últimas representa beneficios para todos. (Kaufmann, 2001, pág. 34). A su vez, la Corte Constitucional ordenó a la Procuraduría hacer seguimiento al cumplimiento de la sentencia (Corte Constitucional, T-025 de 2004). Este precepto obedece a las garantías establecidas en los instrumentos internacionales de derechos humanos que regulan los derechos de las personas víctimas de la migración forzada (Sandoval Mesa y Ubajoa Fierro, 2020, pág. 17).

No obstante, es indudable que se plantean ideales de justicia esenciales para estos aspectos, pero de allí a su implementación solo aparece la normativa de restitución de tierras que alrededor de estos aspectos constituye un inicio en el cumplimiento y la realización de este tipo de derechos fundamentales, como son el derecho a la igualdad y garantía de protección de grupos vulnerables, el derecho a la paz y el derecho a la libertad, en términos de libre circulación por el territorio nacional, junto con los demás derechos que realizan la vida, la libertad y el bienestar de la persona en este sentido (Constitución Política de Colombia, arts. 13, 22 y 24; Younes Moreno, 2021, págs. 104 a -120).

Posteriormente en la Sentencia T-821 de 2007 la Corte Constitucional estableció que las personas que han sido despojadas u obligadas a abandonar su tierra tienen el derecho fundamental a que el Estado «conserve su derecho a la propiedad o posesión y les restablezca el uso, goce y libre disposición de esta» (Corte Constitucional, T-821 de 2007).

Igualmente, esta sentencia recordó los instrumentos jurídicos internacionales y las normas de soft law que consagran la protección de la propiedad o la 
posesión de las víctimas del conflicto. Así por ejemplo los Convenios de Ginebra de 1949, los Principios «Pinheiro, Principios Deng», etc. En efecto, la normativa procedente tanto de los derechos humanos como del derecho internacional humanitario implica que una vez cese la amenaza o el peligro para la persona en su territorio, ella debe ser retornada a su lugar de procedencia. En el derecho internacional humanitario, este desplazamiento se debe únicamente si la necesidad militar y la exigencia de protección se requieren en el caso particular, con el compromiso en igual sentido de las fuerzas militares del retorno de los civiles a su domicilio (Sandoval Mesa y Ubajoa Fierro, 2020). En muchos de los casos de desplazamiento en Colombia esta preceptiva no se cumple y, por el contrario, lo que genera es fenómenos de migración forzada.

Además de ello los instrumentos que protegen a las víctimas del desplazamiento forzado, como el Estatuto de Roma, reprimen esta conducta que se encuentra regulada en el derecho interno tanto cuando opere una situación de conflicto como en tiempos de violencia sistemática y generalizada. Generalmente estas dos situaciones confluyen en el fenómeno analizado y revelan la acción tanto en los actores subversivos como en los grupos de delincuencia organizada. Para desmovilizar población se requiere de una estructura armada de poder que tenga diversas funciones y rangos de acción para generar el temor necesario para el despojo en materia penal, tal y como se observa de manera coincidente en las decisiones de justicia y paz que regulan la condena punitiva para este tipo de organizaciones (Sandoval Mesa y Ubajoa Fierro, 2020; Sandoval Mesa, 2019, págs. 82 y 121).

Adicionalmente, la Corte Constitucional ha establecido que dado el carácter fundamental del derecho a la restitución de tierras, se impone una serie de obligaciones por parte de las entidades del Estado con el objetivo de garantizar la reparación a las víctimas del conflicto armado interno (Corte Constitucional, C-330 de 2016). Sin embargo, en muchas ocasiones aparece el llamado en las sentencias de la Corte Constitucional al Estado para el cumplimiento de los efectos de justiciabilidad de los derechos involucrados, sobre todo en la parte resolutiva de la decisión. No obstante, las acciones emprendidas no colman las aspiraciones de justicia mencionadas.

Al final tales esfuerzos constituyen el desarrollo más representativo de efectividad de los derechos, pese a las múltiples dificultades que enfrenta el aspecto preciso de la restitución y la protección posterior de las víctimas. En este campo, los insumos que se han mencionado pueden servir de base para que, en el escenario de la Jurisdicción Especial para la Paz, se puedan armonizar las medidas de restitución y las medidas punitivas del Estado. 


\section{CONCLUSIONES}

Es necesario analizar que la dinámica del conflicto en Colombia tiene una vinculación necesaria a la cuestión agraria que generó un contexto en el que se identificó una conducta sistemática de violencia por temor, que mantuvo sus organizaciones criminales hasta la actualidad. Este patrón asociado a la tierra mantiene una estructura criminal de grandes estructuras que permanecen vinculadas a factores de poder especial para incidir no solo en los actos violentos de grupos armados sino también en el despojo de tierras, tal y como se muestra en precedentes asociados a estos comportamientos.

El despojo de tierras, así como fue objeto motivado por los actos de múltiples violaciones y crímenes de derechos humanos, entre ellos el desplazamiento forzado, tiene como base elementos que dieron lugar a la legislación especial de restitución que ofrece un proceso contencioso que permite a las víctimas una posibilidad de retorno a sus lugares de origen y a sus actividades perdidas por el despojo de sus bienes. La protección constitucional en este caso ha permitido la permanencia de la ley para que la vía de restitución pueda suplir los mecanismos de restauración que no bastan desde el fundamento penal, toda vez que en su competencia basta la persecución de la conducta.

En este sentido, el proceso posterior cumplido bajo parámetros de temporalidad de la norma desde hace 10 años de existencia de la unidad especial de restitución ha permitido un saldo favorable de hectáreas entregadas a las víctimas que fueron despojadas; sin embargo, su procedencia todavía se encuentra motivada por las zonas que ofrezcan seguridad para el retorno de las víctimas. En este caso, los aspectos que han permitido la renovación de la normatividad de restitución posibilitan un proyecto continuo de retorno de víctimas despojadas que en múltiples casos han sido objeto de desplazamiento forzado, aspecto que permite plantear una de las causas de superación del conflicto y el desarrollo sostenible de la sociedad.

Las acciones de restitución y los procesos contenciosos implementados en tal virtud, junto con las acciones penales, determinan que el retorno de las víctimas a sus tierras despojadas posea una mayor reparación frente a las víctimas, dadas las garantías de entrega de predios y demás proyectos complementarios. De paso, identifica los actores del conflicto involucrados en las acciones; otro elemento necesario para desvelar las estructuras que ocasionaron la conducta. Los efectos de tales acciones judiciales se comienzan a revelar en zonas que ofrecen seguridad de retorno a las víctimas; sin embargo, todavía se cuestiona que puede ser formal y se desea que se convierta en material; de lo contrario, entramos en el cúmulo de decisiones de la Corte Constitucional, con 
mandatos incumplidos, que en este campo se orienta hacia las acciones de la Unidad de Restitución.

\section{REFERENCIAS}

Acuerdo final para la terminación del conflicto y la construcción de una paz estable y duradera. (2016). Disponible en https://www.jep.gov.co/Normativa/Paginas/ Acuerdo-Final.aspx. Consultado el 27-12-2021.

Álvarez, E., et al. (2015). Colombia. Avances y desafíos de la restitución de tierras a la luz de las Directrices voluntarias sobre la tenencia y la gobernanza de la tierra, en Las Directrices voluntarias y su aplicación desde América Latina. Organización de las Naciones Unidas para la Alimentación y la Agricultura (FAO).

Bernal, E.; Coneo, A.; Guzmán, A., et al. E-justice en las solicitudes de restitución de tierras en Colombia, en La restitución de tierras en Colombia: del sueño a la realidad. Ed: Unidad de Restitución de Tierras, v. págs. 396-408, 2014.

Bernal J., et al. (2016). Reflexiones jurídicas sobre el proceso de paz. Editorial Universidad Externado de Colombia. Bogotá D. C.

Centro Nacional de Memoria Histórica, CNMH. (2015). Una nación desplazada: informe nacional del desplazamiento forzado en Colombia. Editorial Imprenta Nacional, Bogotá D. C. CNMH-UARIV.

Corte Constitucional. (2004). Sentencia T-025 de 22 de enero de 2004. M. P. Álvaro Tafur Galvis.

Corte Constitucional. (2007). Sentencia T-821/ de 5 de octubre de 2007. M. P. Catalina Botero.

Corte Constitucional. (2012). Sentencia C-715/ de 13 de junio de 2012. M. P. Luis Ernesto Vargas Silva.

Corte Constitucional. (2013). Sentencia T-387/ de 28 de junio de 2013. M. P. María Victoria Calle.

Corte Constitucional. (2016). Sentencia C-330/ de 23 de junio de 2016. M. P. María Victoria Calle.

Corte Constitucional. (2015). Sentencia T-679/ de 3 de noviembre de 2015. M. P. Luis Ernesto Vargas Silva. 
Corte Suprema de Justicia, Sala de casación penal. 23.02.2010. M. P. Leonidas Bustos Ramírez.

Duarte Rojas, A. y Cote Poveda, A. (2013). Conflicto armado, despojo de tierras y actividad ganadera: Indagando entre el testimonio no oficial y las cifras estatales en el Departamento del Meta, Colombia. Bogotá. Revista Iberoamericana de Estudios de Desarrollo, 3(1), 32-57.

Fals Borda, O. et al. (1978). La violencia en Colombia. Tomo I. Editorial Taurus, Bogotá D. C.

Grupo de Memoria Histórica, GMH. ¡BASTA YA! (2013). Memorias de guerra y dignidad. Bogotá: Informe del grupo de memoria histórica. Comisión Nacional de Reparación y Reconciliación. Bogotá D. C. Editorial Imprenta Nacional.

Gutiérrez, F. (2014). «Propiedad, seguridad y despojo: el caso paramilitar». Estudios Socio-Jurídicos, 16(1), 43-74.

Juzgado Segundo Civil del Circuito Especializado en Restitución de tierras. Sentencia de restitución de 27 de junio de 2013. Demanda Unidad de Restitución.

Kaufmann, A. (2001). Philosophy of Law. Traducción Luis Villar Borda. Ana María Montoya. Universidad Externado de Colombia. Bogotá D.C.

Ley1448, 2011- Decreto 4801 de 2011. «Conformación, administración» y conservación del Registro de Tierras Despojadas y Abandonadas Forzosamente (RTDAF).

Ministerio de Agricultura. (2014). Colombia es el único país que asumió el reto de restituir tierras en medio del conflicto. . Disponible en https:/ / reliefweb.int/report/colombia/ colombia-es-el-nico-pa-s-del-mundo-que-asumi-el-reto-de-restituir-tierras-en-medio. Consultado el 27-12-2021.

Prieto Sanjuan, R. y Sandoval Mesa, J. A. (2020). Medidas de excepción previas a la justicia de transición en Colombia y sus efectos de legalidad penal. Periodo 19481962. Vniversitas, 69. https://doi.org//10.11144/Javeriana.vj69.mepj

Quinche, R. M. F., Peña, H. R. D. P. y Parada, H. M. M. (2015). El amparo de tierras: la acción, el proceso y el juez de restitución. Editorial Universidad del Rosario. https:/ /editorial.urosario.edu.co/gpd-el-amparo-de-tierras-la-accion-el-proceso-y-eljuez-de-restitucion.html

Sandoval Mesa, J. A. y Ubajoa Fierro, N. C. (2020). Forced displacement in Colombia and its international obligations. Sociology International Journal. Med Crave. 4(3), 7581. DOI: 10.15406/sij.2020.04.0022.

Sandoval Mesa, J. A. y Ubajoa Fierro, N. C. Historical background and Main Causes of the Phenomenon of Forced Displacement and Internal Migration in Colombia. 
(2020). London Journal Press. London Journal of Research in Humanities and Social Sciences. 20(8), Compilation 1.0. Disponible en https:/ /journalspress.com/ LJRHSS_Volume20/1042_Historical-background-and-Main-Causes-of-thePhenomenon-of-Forced-Displacement-and-Internal-Migration-in-Colombia.pdf Consultada el 20.08.2021.

Sandoval Mesa, J. A. (2019). Interpretación constitucional de crímenes internacionales. Editorial Diké: Medellín, Colombia.

Sandoval Mesa, J. A. (2018). La garantía criminal en materia penal y penal internacional. Editorial Tirant Lo Blanch: Valencia, España.

Sandoval Mesa, J. A. y Ubajoa Fierro, N. C. (2020). Desplazamiento forzado en el contexto del Conflicto Colombiano, frente a la naturaleza internacional de la migración.

Revista Iberoamericana de Derecho Internacional y de la Integración ${ }_{t}(12)$, junio. Disponible en https://ar.ijeditores.com/pop.php?option=publicacion\&idpublicacion= 69\&idedicion=3836 Consultada el 19.08.2021.

Sandoval Mesa, J. A. (2017). Formas de autoría en la persecución de crímenes internacionales. Revista Prolegómenos Derechos y Valores, 20(40), 11-26. DOI: http:/ / dx.doi.org/10.18359/ prole.3038.

Situation in the democratic Republic of the Congo in the case of the Prosecutor v. Thomas Lubanga Dyilo, Sentencia de 10 de julio de 2012.

Situation in the democratic Republic of the Congo in the case of the Prosecutor v. Germain Katanga, Sentencia de 4 de abril de 2014.

Torregrosa Jiménez, R. y Torregrosa Jiménez, N. (2012). Justicia transicional: Paz vs. Justicia: el dilema en Colombia. Bogotá: Universidad Libre.

Tribunal Superior del Distrito Judicial de Bogotá, Sala de Justicia y Paz, magistrada ponente Uldi Teresa Jiménez López, Sentencia de 29 de junio de 2010.

UAEGRTD. (2017). Unidad Administrativa Especial de Gestión de Restitución de Tierras Despojadas. Informe de gestión. Bogotá. Consultado el 27-12-2021. Disponible en https:/ / www.restituciondetierras.gov.co/informes-de-gestion. Consultado el 27-12-2021.

Uprimny-Yepes, R. y Sánchez, N. C. (2010). Los dilemas de la restitución de tierras en Colombia. Estudios Socio-Jurídicos, 12(2), 305-342. Recuperado a partir de https:/ /revistas.urosario.edu.co/index.php/sociojuridicos/article/view/1373.

Younes Moreno, D. (2021). Derecho Constitucional Colombiano. Editorial Legis. Décimo séptima edición. Bogotá D. C. 
